\title{
Use and nutritional value of cassava roots and leaves as a traditional food
}

Aurelie Bechoff, University of Greenwich, UK

1 Introduction

2 Diversity in traditional cassava products

3 Products from cassava roots

4 Products from cassava leaves

5 Chemical composition of cassava roots

6 Chemical composition of cassava leaves

7 Anti-nutrients in roots and leaves

8 Case study: biofortified cassava roots made into gari and fufu in Nigeria

9 Future trends

10 Conclusion

11 Where to look for further information

12 References

\section{Introduction}

Cassava is second after rice in importance as a source of carbohydrates in developing and tropical countries, and the fifth most important staple crop globally (FAOSTAT 2013). In developing countries, over half a billion people consume cassava as food and rely on it as important sources of nutrition and income. Cassava's main commercial product is the long tuberous starchy root. Size varies widely, but averages about 5 to $7 \mathrm{~cm}$ diameter and $20-40 \mathrm{~cm}$ long. The root has a mostly dark brown, but sometimes light brown or white, peel, and generally a white or cream interior flesh. Cassava leaves are alternate palmate and smooth leaves with lobes between $7 \mathrm{~cm}$ and $15 \mathrm{~cm}$ long that are also edible (Lancaster and Brooks 1983) (Fig. 1). 

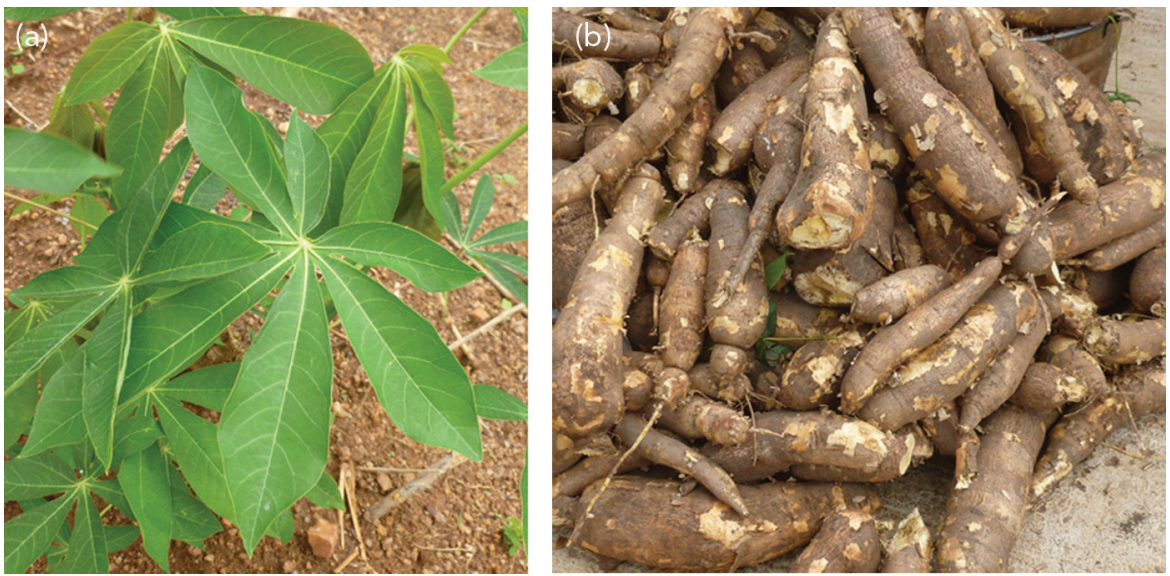

Figure 1 Cassava leaves and plant, and cassava roots a day after harvest. Source: Bechoff, A. 2013, Nigeria.

In Asia, with some exceptions such as Indonesia, cassava is mostly used in non-food applications. Most production is destined for industrial starch for both food and non-food uses, animal feed and ethanol. In Africa, cassava is used mostly for human food and is therefore an important crop for food security.

Cassava was domesticated in the New World, and first introduced to Africa soon after the arrival of Europeans to the Americas. In Africa and other parts of the world cassava has since been fully integrated as part of the local cuisine. Both the starchy and fresh leaves can be used for human consumption to prepare a variety of dishes.

Cassava has many advantages as a food crop in in the tropics: it is drought tolerant, and can yield relatively well in poor soils, though it will also respond well to good management. It does not have a defined maturity period, and roots can be stored in the soil for long periods, allowing flexibility of harvest on an as-needed basis for food or for sale. Cassava is a cheap source of carbohydrates and therefore of energy. Under relatively harsh climate conditions and with little input, cassava can often produce more energy per hectare than any other crop. The versatility of cassava has made it become a source of livelihood to about 300 million people in sub-Saharan Africa, with many of them being poor smallholder farmers. With the new challenges coming up in the twenty-first century such as global warming and increase in world population, cassava's role in food security is likely to increase in the years to come.

Although the cassava crop has many qualities, it also presents a number of weaknesses or challenges:

- Cassava roots and leaves contain cyanogenic glucosides, which release the highly toxic hydrogen cyanide ( $\mathrm{HCN})$ on hydrolysis. Cultivars with low levels - below approximately 100 ppm - are said to have low cyanogenic potential (CNP) and are typically referred to as sweet. These roots may be eaten directly after boiling or frying. Cultivars with higher CNP are referred to as bitter (although CNP is not a precisely related to level of bitterness), and require exhaustive processing in order to reduce these compounds to safe levels. In all places where cultivars with high 
CNP are traditionally grown, people have developed effective ways to reduce toxicity through processing techniques and poisoning is normally rare.

- Cassava roots have a short shelf life of 2-3 days after harvest. Growers and consumers overcome this constraint by quickly processing or consuming the roots (Blagbrough et al., 2010; Sánchez et al., 2010).

- Cassava roots are composed mostly of starch and contain very few proteins and other micronutrients of importance for a balanced diet. High consumption of cassava roots without other complementary foods can lead to hidden hunger, that is, deficiency of micronutrients such as vitamins and minerals. Cassava leaves, on the other hand, contain some proteins and vitamins that could compensate the lack of the nutrient in roots, but the leaves are often underutilized for human food.

\section{Diversity in traditional cassava products}

The main constraint of cassava for direct use is its cyanogenic potential. Both roots and leaves can contain high amounts of cyanogenic compounds that can potentially be harmful if the products are not correctly processed. This feature of cassava has resulted in the development of numerous processed products. The processing method and the number of processing steps are linked to the level of cyanide content (sweet or bitter varieties). We have focused on traditional African products in this review; however, it should be noted that traditional products of cassava can also be found in other parts of the world (i.e. in Central/South America where many of the African products have an ancient origin).

Cassava roots also have a very short shelf life at ambient temperature under tropical conditions (24-48 h) (Westby 2002), which requires rapid consumption or processing after harvest.

\section{Products from cassava roots}

Products can be divided into two categories:

1 Non-fermented products that are processed to a stable or consumable form in a single step. This applies mainly to sweet cassava (e.g. boiling or frying) and to the intermediate cassava products of either sweet or bitter cassava, such as dried cassava chunks, flour and starch;

2 Fermented products that are made by several steps of processing. This applies mostly to the bitter-type varieties that require cyanide detoxification. Roots and leaves contain enzymes (i.e. $\beta$-glucosidase) that are released from the cell vacuoles during processing and cleave the cyanogenic compounds when put into contact through processing such as grating or pounding. Subsequent operations (i.e. fermentation; cooking or roasting) are important to ensure that cyanide is fully volatilized from the product. There are two different types of root fermentation: a solid-state fermentation (directly on the mash) or a submerged fermentation or soaking of the whole roots. 


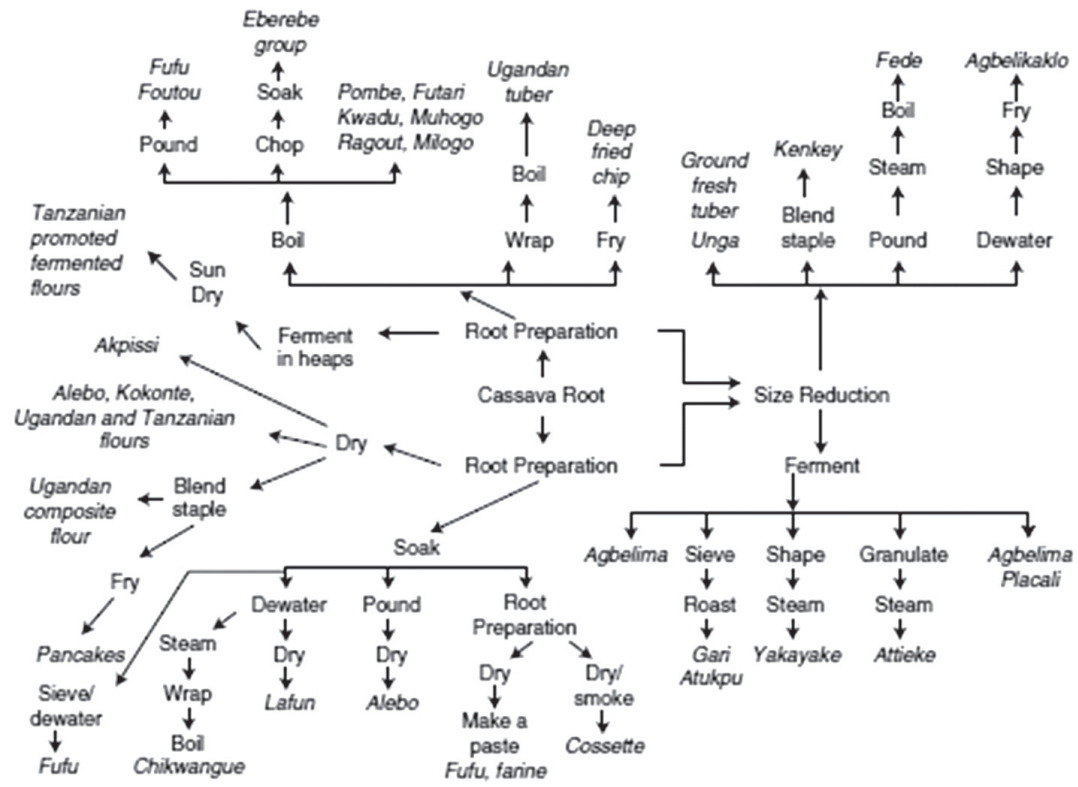

Figure 2 Interrelationship of cassava products from 233 villages in 6 African countries. Source: Westby, 2002.

Figure 2 presents examples of the many different types of products that can be encountered in Africa. Cassava products are made through several steps of processing. Cassava roots undergo peeling, followed by a size reduction (e.g. grating or chopping), boiling or soaking. This is followed by fermenting and/or drying. A large variety of products can be prepared using a combination of different steps.

\subsection{Non-fermented products made in a single-step process}

Sweet varieties of cassava (that may contain low levels of cyanogenic compounds) are used for processes that generally involve only a single step because of the low initial cyanogenic compound that can be reduced easily to a safe level for consumption. High dry matter content varieties are generally preferred because the texture is firmer and less moist.

Boiling or frying are the most common processes. After peeling, roots can be processed as whole or as chunks or slices. Cooked or boiled cassava as whole roots or pieces of different varieties have diverse tastes (e.g. variable sweetness) and texture (e.g. different levels of stickiness, or softness) (Charoenkul et al., 2006; Hongbété et al., 2011).

\subsection{Non-fermented products made into industrial products}

Intermediate or industrial products are in most cases non-fermented because the quality can be better controlled on non-fermented products rather than on spontaneously fermented ones. The quality of intermediate products has to comply with quality standards because these are industrial products. 
In Asia, starch, also called tapioca, is one of the most common products derived from cassava roots. The product is odourless, bland in taste and not sour, with low particle size $(<250 \mu \mathrm{m})$ and a minimum of $95 \%$ starch (ARS 2012). Cassava starch, also called tapioca, is used as a thickener and a stabilizer in various industries (soups, baby food, confectionary, glue and adhesives, pharmaceuticals, detergent soaps, textile etc.)

The use of dried chips is a traditional intermediate product for industry and also for animal feeding in Asia and Latin America, but becoming increasingly popular in Africa as well. Cassava roots can be chopped as irregular chunks or uniform slices and dried. Pellets of regular shape and size may be produced using a pelleting machine that compresses and dries the products. It is essential that the chips or pellets are well dried, ideally to not more than $14 \%$ moisture, for a good storability (Falade and Akingbala 2010). Dried cassava can also be ground into flour for use in different food and non-food applications.

The Natural Resources Institute (NRI) of the University of Greenwich, UK, in collaboration with other local partners, has been promoting for many years the use of High Quality Cassava Flour (HQCF), especially in Africa where there is scope in the market for improved cassava processed products. HQCF is a flour of industrial quality that can be used in multiple applications such as a partial substitute for wheat flour in the baking industry or substitute for maize flour, maize or cassava starch in various industries. Good-quality roots are selected based on high dry matter content, absence of rots, root form, and age (10-12 months). Roots are processed to meet specific quality criteria. For instance, roots are grated rather than chipped, to minimize cyanogenic residues. The mash is then pressed using a hydraulic press instead of a manual press as used in more rudimentary processing. Pressed wet cake is dried with a maximum loading and the final moisture content is between $10 \%$ and $12 \%$. The milled and sieved flour should have a particle size $<0.25 \mathrm{~mm}$. The roots should be processed in less than $24 \mathrm{~h}$ to meet HQCF quality standards. HQCF can be used to substitute other types of flours, including maize or wheat, and also starch in the food industry for products such as bread, biscuits and confectionary products.

\subsection{Products fermented by water submersion}

Fermentation by submersion means that whole cassava or pieces of cassava are immersed in water and left to ferment for several days.

Fermentation has long been used as a means of food preservation, and it is a process with an ancient history in cassava that fermentation of cassava is a process by which specific and appreciated product flavours are developed, and the multiplication of lactic acid bacteria that acidifies the medium limits the proliferation of undesirable and pathogenic microorganisms (e.g. E. coli).

\subsubsection{Fufu}

Fufu refers to different products depending on the country where it is found. In Ghana, fufu is a non-fermented paste made out of roots from sweet varieties that are boiled and pounded. In Nigeria, fufu refers to a fermented dough that is made of cassava (whole or slices) steeped in water and fermented for up to three days, sieved and then cooked into a homogeneous paste. Fufu is one of the staple foods in both these countries. Fufu develops its typical taste and aroma during fermentation. A smooth texture, a characteristic aroma and a homogeneous colour are important quality criteria for the consumers (Falade and 


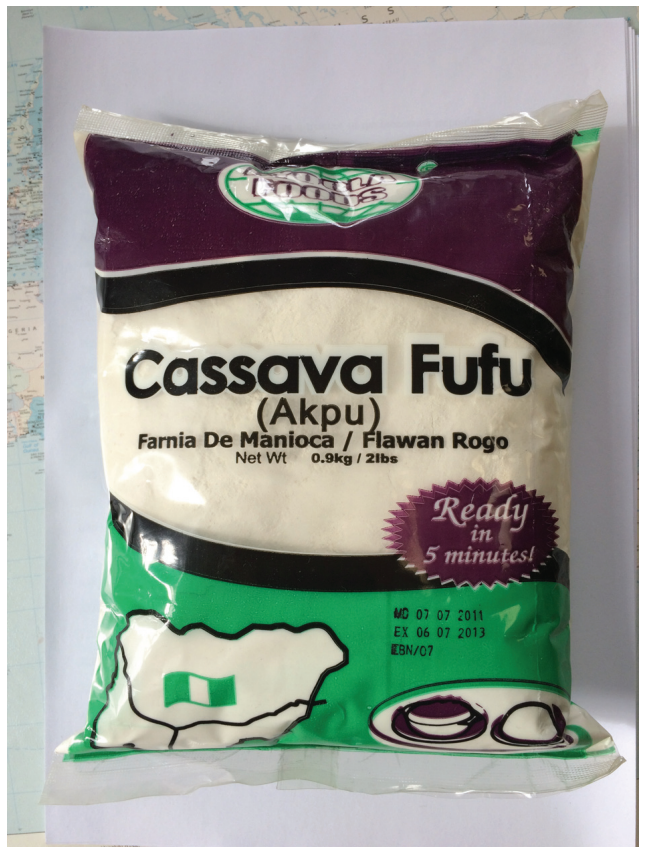

Figure 3 Dried fufu from Nigeria exported to UK, Belgium, the Netherlands, United States, Canada and Australia.

Akingbala 2010; Oyewole and Ogundele, 2004; Tomlins et al., 2007). Fufu can also be dried to increase its shelf life and to reduce transportation costs, especially for export (Fig. 3).

\subsubsection{Lafun}

Lafun is a fibrous flour popular in Nigeria. When reconstituted into a paste it looks similar to fufu. In the traditional lafun preparation, fresh cassava roots are cut into chunks and steeped for 3-4 days or until the roots become soft. Chunks are then sun-dried for several days (often on the side of the road) and then milled into flour. Unlike fufu, lafun is not sieved and therefore the fibres are still present, which gives it a coarser texture (Cassava Biz 2005; Oyewole and Afolami 2001).

\subsubsection{Chikwangue and 'bâton de manioc'}

Chikwangue, also called cassava bread, and similar products such as 'bâton de manioc' (Fig. 4) are common forms of cassava consumption in Central Africa, in mostly Frenchspeaking countries (i.e. Cameroon, Gabon, Congo, DRC). Chikwangue and 'bâton de manioc' are prepared by peeling and chopping roots into pieces that are left covered in water for about 2 days. Afterwards central fibres are removed, the pieces washed with clear water, squeezed and made into a smooth paste. The paste is then wrapped in young leaves (Megaphrynium macrostachyum, or other species of Marantaceae (arrowroot family)) bound with raffia grass and boiled or steamed. Sometimes the product is pre-gelatinized 


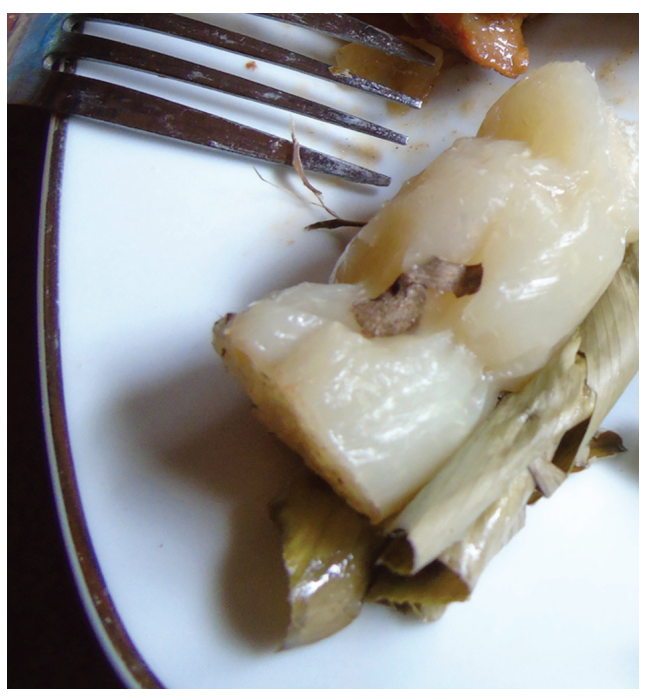

Figure 4 Baton de manioc ready for consumption. Source: Bechoff, A., Cameroon, 2015.

in the first cooking and cooked fully in a later cooking (O'Brien et al., 1992; Agbor-Egbe and Mbome 2006; Treche et al., 1995).

\subsection{Solid-state fermented products}

As opposed to submerged fermentation, solid-state fermentation is conducted directly on the product without addition of water. Cassava roots are generally processed into a mash that is then fermented for variable periods (1-5 days). In most cases, fermentation is a spontaneous one where the indigenous floras present in the mash are responsible for inducing the fermentation. A drying step sometimes is added after the fermentation in order to obtain a product with a longer shelf life.

\subsubsection{Gari and kpokpogari}

Gari is a slightly acidic and semolina-like food product that is very popular in West Africa (e.g. Benin, Nigeria). In Nigeria, gari is the main staple food and therefore plays an important role in food security. Gari is made by peeling (washing), grating, fermenting, pressing and roasting cassava. Gari can equally be eaten dry or reconstituted into a paste (using boiling water) called eba. There are different types of gari based on the duration of fermentation, the size of the granule, addition of red palm oil etc. Levels of quality are based on the physicochemical characteristics of the roots, the hygiene practices and degree of coarseness (Achinewhu et al., 1998). Ability of gari to swell when reconstituted into eba by the addition of boiling water may also be an important quality criterion (Blanshard et al., 1993; Irtwange and Achimba 2009; Oduro et al., 2000; Owuamanam et al., 2010).

Kpokpogari is a variant product from gari that is popular in the Niger Delta area of Nigeria. During processing of kpokpogari, the starch portion of the product is separated 
from the fibrous portion by sifting with addition of water. The fibrous part is collected and after fermentation roasted in a hot pan. During the roasting step, the mash is constantly stirred until obtaining an intermediately dried product (kpokpogari) with granules that are larger than common gari (Sanni et al., 2005).

\subsubsection{Attieke}

Attieke is a semolina-like product popular in Côte d'Ivoire, similar to gari and kpokpogari. The initial steps of preparation are similar to gari but the latter steps involve sun drying and steaming instead of roasting. Attieke has a slightly sour taste and is similar to couscous in appearance (Djeni et al., 2011).

\subsubsection{Agbelima}

Agbelima is a fermented dough commonly consumed in West Africa (i.e. Ghana, Togo and Benin). Processing steps are peeling, grating and fermenting similarly to other solid fermented products. However, as opposed to gari and fufu products that undergo spontaneous fermentation, the preparation of agbelima involves addition of kudeme, a traditional fermentation inoculum, which aids the breaking down of the texture through the activity of a number of tissue-degrading enzymes. The product is mostly consumed in a wet form. A dried form (flour) was however developed by FRI (Food Research Institute) in Ghana, but the local consumption is still marginal and the flour is mostly promoted for exportation (Dziedzoave 1996; Dziedzoave et al., 1999; Dziedzoave et al., 2000).

In summary, the products made from cassava roots are of different types (non-fermented or fermented; dried or wet) and the choice of the process is generally based on the cyanogenic potential of the roots (either sweet or bitter varieties). Food products made using single step were boiled or fried whole roots or pieces from sweet varieties whilst products made using several steps were fufu, lafun, chikwangue, and gari, agbelima and attieke from bitter varieties mostly. Products are often regional and the preparation varies from one ethnical group to another. In addition, the type of products made are climate related: for example, wet products such as baton, fufu are mostly produced in tropical humid climates whilst products such as lafun that require sun drying are preferably made under drier and more Sahelian climates.

\section{Products from cassava leaves}

Cassava is mostly grown for its starchy roots. However, the stem, leaves and petioles are also edible (Lancaster and Brooks 1983; Latif and Müller 2015). The consumption of cassava leaves is not as frequent as that of cassava roots, but they are nutritious and their consumption together with the roots could add valuable proteins and vitamins to the diet. Cassava leaves are consumed mostly in Central Africa (Congo, DRC, Angola, Gabon, Central Africa, Liberia etc.), South and South-east Asia (Indonesia, Malaysia, Sri Lanka) and Brazil (Latif and Müller 2015).

\subsection{General process}

The number of recipes for cassava leaves is not as considerable as for cassava roots. The basis of most recipes is similar: the first step of cassava leaves preparation generally 
involves chopping, grinding or pounding (i.e. for about 15 minutes) followed by cooking. Cooking duration is variable (15-60 minutes). Boiled cassava leaves have the appearance of cooked spinach. Depending on how much water is removed, the cooked product may be a thick paste or a thinner stew. There are a number of variants, based mostly on the different ingredients added to the leaves.

\subsection{Different recipes}

Cassava leaves play an important part in the diet in Congo, accounting for about $60 \%$ of the vegetable consumption. Cassava is considered as 'all sufficient' in Congo - a complete meal - because people get 'bread' from the roots and 'meat' from the leaves. Cooked cassava leaves are also called 'old man's meat' because little chewing is required (Achidi et al., 2005; Latif and Müller 2015). Sakasaka is a popular dish in both Congo and Sierra Leone; leaves are sometimes blanched before the pounding step (Achidi et al., 2005). Eggplants and onions can be added during pounding. During cooking, palm oil or groundnut paste may be added. Cooking time is about 60 minutes and by the end, the water is mostly evaporated. However, another variant of this dish uses bicarbonate and requires less water; cooking time is also reduced because of the bicarbonate properties (Achidi et al., 2005). Sakasaka is served as a side with meat or fish and 'baton de manioc'/ chikwangue or rice. Sometimes cassava leaves are sun-dried before pounding, as reported in Angola and DRC (Lancaster and Brooks 1983).

Although Nigeria is the main producer of cassava in the world, cassava leaves are not commonly consumed. In some areas of Nigeria, however (eastern parts: Benue State), some tribes regularly consume cassava leaves. Sweet cassava varieties called 'red sweet cassava' are selected and the youngest soft leaves from the fresh top are collected. The petiole of the leaves is reddish in nature, unlike the more common green petiole. Leaves are washed with water, squeezed and prepared in the form of egusi (melon seed). Cooking is 10-15 minutes. The dish is served with pounded yam, maize flour dough or a cassava root dish such as akpu and eba.

Researchers at IITA in Nigeria, working with HarvestPlus, are promoting the consumption of cassava leaves and have adapted recipe for amaranth leaves to cassava leaves. The condiment recipe is based on a typical Nigerian Yoruba recipe (Fig. 5):

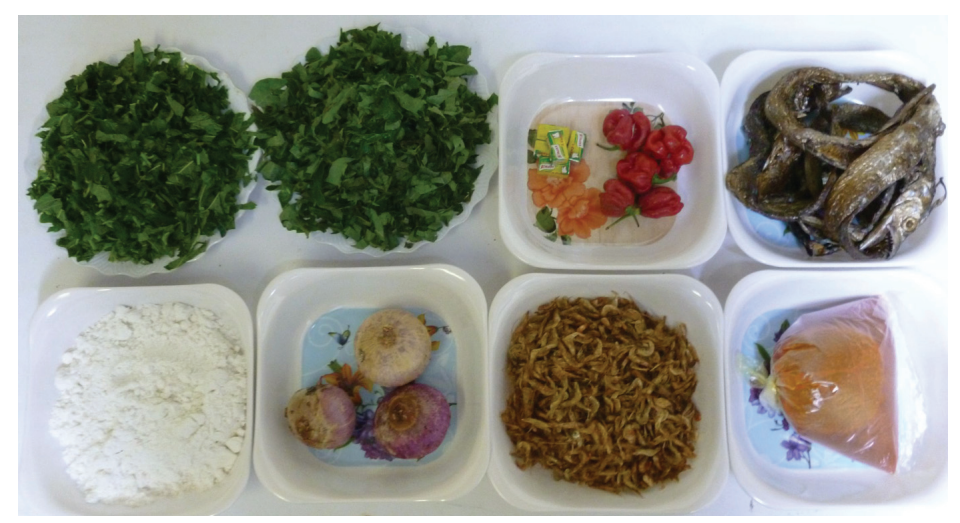

Figure 5 Ingredients for cassava leave recipes developed in Nigeria. Source: Bechoff, A., 2013. From left to right: Cassava leaves; Knorr cubes; red hot pepper; dried fish; salt; onions; cray fish; palm oil. 
Ingredients for $500 \mathrm{~g}$ of ground leaves: Palm oil (350 g); Red peppers (5 pieces) (60 g); Knorr cubes (4); Dried fish (213 g without bones); Cray fish (160 g); Salt (4 g); Onions (3 medium size) sliced ( $260 \mathrm{~g}$ )

Nigerian recipe: Fry the onions in palm oil, add pepper juice. Add dried fish (without bones) and pounded Cray fish. Add Knorr cubes. The sauce is ready after about 10-15 minutes.

Boil the thawed ground leaves for about 10-15 minutes. Add the sauce and cook for a further 1-2 minutes. The quantity of leaves/sauce was selected by local cooks according to the Yoruba traditional practices. The ratio thawed ground leaves/sauce was 1.3/1.0.

Table 1 Proximate, vitamin and mineral composition of cassava roots and leaves. Source: Montagnac et al., 2009a; USDA food composition cassava, 2015 ; Latif \& Müller, 2015c

\begin{tabular}{|c|c|c|c|}
\hline & $\begin{array}{l}\text { Proximate composition } \\
\text { (for } 100 \mathrm{~g} \text { ) }\end{array}$ & Cassava roots & $\begin{array}{l}\text { Cassava leavesa, (dry } \\
\text { weight basisc) }\end{array}$ \\
\hline & Food energy (kJ) & $526-611$ & $209-251$ \\
\hline & Dry matter (g) & $30-40$ & $10-30$ \\
\hline \multirow[t]{5}{*}{ Macronutrients } & Protein (g) & $0.3-3.5$ & $1.0-10.0(17.7-38.1)$ \\
\hline & Lipid (g) & $0.03-0.5$ & $0.2-2.9(3.5-7.3)$ \\
\hline & Carbohydrate (g) & $35-38$ & $7.0-18.3(31.9-64.7)$ \\
\hline & Dietary fibre (g) & $0.1-3.7$ & $0.5-10.0$ \\
\hline & Ash (g) & $0.4-1.7$ & $0.7-14.5(4-16.1)$ \\
\hline \multirow[t]{5}{*}{ Vitamins } & B1: Thiamine (mg) & $0.03-0.28$ & $0.06-0.31$ \\
\hline & B2: Riboflavin (mg) & $0.03-0.05$ & $0.21-0.74$ \\
\hline & B3: Niacin (mg) & $0.6-1.1$ & $1.3-2.8$ \\
\hline & $\begin{array}{l}\text { C: Ascorbic acid (mg) } \\
\text { (vitamin C) }\end{array}$ & $15-50$ & $60-370$ \\
\hline & A: Carotenoids $(\mu \mathrm{g})$ & $5-35$ & $8300-11800$ \\
\hline \multirow[t]{9}{*}{ Minerals } & Calcium (mg) & $16-176$ & $37-708(430-1140)$ \\
\hline & Phosphorus (mg) & $6-152$ & $27-211(180-420)$ \\
\hline & Iron (mg) & $0.27-14.0$ & $0.4-8.3(15-27)$ \\
\hline & Potassium (g) & $0.25-0.27$ & $0.35(1.4-2.3)$ \\
\hline & Magnesium (g) & 0.03 & $0.12(0.26-0.37)$ \\
\hline & Copper (ppm) & 2.0 & $3.00(40-70)$ \\
\hline & Zinc (ppm) & 14 & $71.00(120-210)$ \\
\hline & Sodium (ppm) & 76 & $51.0(380-1200)$ \\
\hline & Manganese (ppm) & 3 & $72.0(160-250)$ \\
\hline
\end{tabular}

Note: Values are indicated on a fresh weight basis except those between brackets ${ }^{c}$. 
Table 1 summarizes the proximate, vitamin and mineral composition of cassava roots and leaves.

The chemical constituents comprise the macronutrients (carbohydrate, fat, lipid, protein, fibres) and the micronutrients (vitamins, minerals). Cassava chemical composition is determined by both genes and the environment.

\section{Chemical composition of cassava roots}

\subsection{Macronutrients}

Carbohydrate content is high (35-38\% fresh weight) - a result of the high starch content of cassava. For this reason cassava roots are considered mostly as an energy food (Montagnac et al., 2009; Burns et al., 2012). Cassava contains more carbohydrates than potatoes and cereals (i.e. wheat, rice, maize and sorghum). The main simple sugars are sucrose, glucose, fructose and maltose. Total sugars range from $0.2 \%$ to $18.8 \%$, with $3.7 \%$ on average and reducing sugars between 0 and 15.7 with 1.2\% on average (Sánchez et al., 2009). In sweet cassava varieties, up to $17 \%$ of carbohydrates were sucrose and there were small amounts of dextrose and fructose (Montagnac et al., 2009). Bitter varieties were shown to have higher total sugar levels than sweet ones in a study by Padonou et al. (2005). Higher sugar levels in some bitter varieties could mask the bitter taste of the cyanogenic glucosides.

Of the carbohydrates in cassava roots, starch occupies about $85 \%$ on a dry weight basis (Sánchez et al., 2009; Sayre et al., 2011). Starch properties are related to the amylose/ amylopectin ratio. Amylose content is $15-20 \%$ on average but high-amylose mutants with up to $30 \%$ amylose have been found (Ceballos et al., 2007). Because of the high proportion of starch, there is a strong positive correlation between starch content and dry matter content in roots, on a fresh basis. Starch quality and content are influenced by both genetics and growing conditions linked to the environment (soil water availability; temperature; soil type and soil nutrient status) (Sánchez et al., 2009).

Fibre content- quite low in roots - ranges from $0.1 \%$ to $3.7 \%$, and is influenced especially by root age.

Protein and lipid contents (up to $3.5 \%$ and $0.5 \%$, respectively) are considered low in cassava compared to seed products such as the grains. Lipid content of cassava was lower than that found in maize and sorghum; however, it was higher than that found in potato and comparable to rice (Montagnac et al., 2009). The protein content was much lower than that of maize and sorghum, which have about $10 \%$ protein. In cassava roots, half of the protein content consists of whole proteins, whereas the other half is amino acids. Some essential amino acids such as methionine, cysteine and tryptophan are present in very low quantities; nonetheless, other compounds such as arginine, glutamate and aspartate are present in substantial amounts (Montagnac et al., 2009). Chavez et al. (2000) believed that there is space for improvement in protein in cassava roots through breeding. A screening of cassava varieties (Chávez et al., 2005) from various parts of the world revealed that many varieties from Central and South America have higher protein contents in the roots, and this was believed to result from natural introgression of genes from wild relatives. The diversity of protein content found in nature for cassava roots gives hope that there are ways for higher protein cassava varieties to be developed either using conventional breeding or through genetic engineering. Nonetheless, it should be recognized that cassava storage roots evolved primarily as a means to store energy 
(starch) for regrowth after a stress period (primarily drought), and they are not well suited to accumulate high levels of proteins. Additionally, farmers and consumers also would have focused their selection of varieties on the basis of starch yield and quality rather than protein.

\subsection{Minerals and vitamins}

Cassava roots contain calcium, iron, potassium, magnesium, copper, zinc and manganese in levels comparable to those of many legumes (Montagnac et al., 2009). Chavez et al. (2000) reported average levels of $590 \mathrm{mg} / \mathrm{kg}$ of calcium on a dry matter basis.

Levels for iron and zinc of $9.6 \mathrm{mg} / \mathrm{kg}$ and $6.4 \mathrm{mg} / \mathrm{kg}$, respectively, were reported in roots (Chavez et al., 2000). These levels were considered low to meet nutritional requirements according to Burns et al. (2012), and there is a need to improve these essential minerals in cassava. To date, there have not been concentrated attempts to improve iron and zinc through conventional breeding techniques so the potential for improvement is unknown. Limited content of these minerals in most soils where cassava is grown may limit success. Improvement of mineral content using transgenics or gene editing could also provide a more successful route.

Vitamin C (ascorbic acid) content in cassava roots is relatively high - from 15 to 45 $\mathrm{mg} / 100 \mathrm{~g}$ in the edible portions (Montagnac et al., 2009). On the other hand, low amounts of the $B$ vitamins (thiamin, riboflavin and niacin) were reported. Vitamins $C$ and $B$ are labile and their content was reported to significantly lower during processing.

Products from cassava roots are often staple foods and therefore critical to food security in sub-Saharan Africa, especially by providing the carbohydrate component of the diet. Mineral and vitamin levels in cassava roots are overall lower than in most cereals, legumes and other root and tuber crops. In addition, these levels are further reduced during processing. Cassava roots are high sources of energy but have low protein, fat, and lack essential minerals and vitamins (Montagnac et al., 2009). Products from cassava roots therefore require either genetic improvement and/or addition of other dishes that can complement these deficiencies (e.g. sauce, meat, fish and vegetables - including cassava leaves). The strategy (genetic improvement or diet diversity) will depend on the particular nutritional component and the relative access to genetic diversity versus access to diverse diets. In many cases, a combined, complementary approach can be used.

\section{Chemical composition of cassava leaves}

Leaves contain less carbohydrate than roots but have more nutrients that are essential to tackle hidden hunger, such as vitamins and minerals.

The nutrient composition of leaves depends on a number of factors: variety of cassava, age of the plant, age of the leaves (young to mature) and size of the leaves (Montagnac et al., 2009; Latif and Müller 2015).

\subsection{Macronutrients}

The carbohydrates in cassava leaves are mainly starch, with amylose content varying from $19 \%$ to $24 \%$ (Montagnac et al., 2009), levels similar but slightly higher compared to the 
roots. Leaves contain about three times less carbohydrate than roots but more protein, lipid, fibres, minerals and vitamins (Montagnac et al., 2009).

Although Montagnac et al. (2009) reported values of protein levels of up to $10 \%$, Chavez et al. (2000) mentioned that levels could reach 30\% (DW basis) and showed that leaf protein could be an important nutritional supplement to the roots that had very low protein content. It was reported that cassava leaves have an essential amino acid content higher than soya bean protein. The total protein content of cassava leaves is 5 to 10 times to that of roots and is equivalent to the protein content of egg $(10.9 \mathrm{~g} / 100 \mathrm{~g})$ (Montagnac et al., 2009; Latif and Müller 2015). However, in terms of amino acid balance, methionine and isoleucine are deficient whilst lysine levels are higher when compared to egg. Cassava leaves could be a valuable source of lysine to complement lysine-deficient diets such as rice, wheat, sorghum, and millet (Lancaster and Brooks 1983). However, processing can significantly reduce these levels by denaturing amino acids, as was reported by Lancaster and Brooks (1983).

\subsection{Minerals and vitamins}

Cassava leaves are rich in minerals (potassium, phosphorus, magnesium and calcium) and vitamins (B1, B2, C and A) (Montagnac et al., 2009).

Leaves contain about 100 times more calcium than the roots and 2-3 times more phosphorus. Leaves are also concentrated in other minerals such as potassium, magnesium, copper, zinc, iron and manganese. However, the levels of manganese, zinc, iron, copper and sodium are lower than other crops according to Latif and Müller (2015). Montagnac et al. (2009) nonetheless reported that iron and zinc levels are equivalent to those found in sweet potato leaves. Calcium is comparable to the levels found in broccoli and magnesium content is more than in broccoli but lower than in sweet potato leaves. Overall Montagnac et al. (2009) stated that the mineral content of cassava leaves was similar to that most other leaves.

The vitamin content of cassava leaves is high: Vitamins B1 (thiamin) and B3 (niacin) levels are more than that of legumes and leafy legumes with the exception of soya bean. Compared to roots levels of B1 and B3 in cassava leaves are 4 to 5 times more. In addition, B1 and B3 levels surpass some of the contents in animal products such as fresh egg, cheese and whole milk. Vitamin B2 (riboflavin) content surpasses levels of all of the above, including soya bean and is about 10 times more than that of roots (Montagnac et al., 2009).

The vitamin A (carotenoids) content of cassava leaves was superior to that of other legumes and leafy legumes and the vitamin $C$ content was also high compared to other vegetables. Levels of carotenoids (vitamin A) are about a 1000 times more in leaves compared to roots (Montagnac et al., 2009). Vitamin E is low in both leaves and roots. The processing techniques can lead to large reductions in vitamins, in particular vitamin $C$ that is very labile. In addition, storage of cassava leaves can also lead to reduction in vitamin C (Lancaster and Brooks 1983). Vitamin B was reduced by half while boiling and only slightly reduced during steaming (Lancaster and Brooks 1983). Vitamin A or carotenoids can also be affected, slightly in boiling and steaming and more drying followed by storage. Leaves are used as a by-product, used for animal feeding, or often simply discarded. They are an important part of nutrient recycling when allowed to remain in the field. Although leaves are nutritious, their use is as not as common as the roots. Reasons might be palatability and lack of knowledge of their nutritional properties, but also the higher levels of antinutrients compared to the roots, which requires exhaustive processing to reduce them to a safe level. 


\section{Anti-nutrients in roots and leaves}

The main nutritional constraint of both roots and leaves is the need for detoxification due to the presence of cyanogenic compounds. It should be noted that cassava leaves also contain other anti-nutrients such as high fibre content, tannin, polyphenols and phytate that reduce nutrient bioavailability (Latif and Müller 2015). Methionine availability in particular is negatively influenced by the presence of tannins (Latif and Müller 2015).

Non-protein nitrogen components in cassava roots are nitrite, nitrate and cyanogens. Of all the anti-nutrients, cyanogens are the most toxic compounds present in the cassava leaves and roots. These can be found under three different forms: cyanogenic glucosides (95\% linamarin and 5\% lotaustralin), cyanohydrin and free cyanide. Cyanogenic compounds can cause an upper moto-neuron disease called konzo. The disease results in cerebral damage and epidemic paralysis that is irreversible. Ruminant animals are less vulnerable to these compounds because these animals have an ability to detoxify the leaves in their digestive system.

Cyanogenic potential in the roots varies between 14 ppm and 3274 ppm, with 340 ppm on average (Sánchez et al., 2009). The concentration of cyanogenic compounds in the leaves is $5-20$ times that of the roots, and leaves also have 200 times more linamarase activity (Bokanga 1994).

Figure 6 describes the different steps of cassava detoxification. Cyanogen glucoside (95\% linamarin and 5\% lotaustralin) hydrolysis occurs in cassava mash in presence of linamarase (alpha- $\beta$-glucosidase), an enzyme naturally present in cassava. Linamarase releases acetone cyanohydrin and glucose. Subsequently, acetone cyanohydrin either can be spontaneously cleaved into acetone and hydrogen cyanide or an enzyme (lyase) can act as a catalyst to the reaction. While hydrogen cyanide is readily removed during cassava processing, the presence of residual linamarin and its breakdown product (acetone cyanohydrin) in cassava-based food products has been a cause for concern because of their possible effects on health. Acetone cyanohydrin is stable under acidic conditions and unstable under alkaline conditions.

The hydrolytic enzymes (linamarase and hydroxynitrile lyase) are situated in the cell walls of cassava and are released when the cell matrix is disrupted, for example, by

(a)<smiles>CC(C)(C#N)OC1OC(CO)CC(O)C1O</smiles>

।<smiles>OC[C@]1(O)O[C@@H](O)C(O)C1(O)[GeH2]O</smiles>

II<smiles>CC(C)(C)C#N</smiles>

III

(b)<smiles>CC(C)(O)C#N</smiles>

III

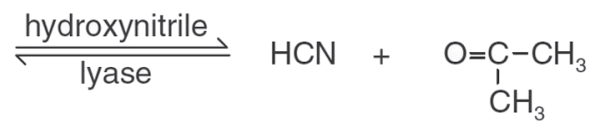

IV

Figure 6 Enzymatic breakdown of linamarin (Compound I); glucose (compound II); acetone cyanohydrin (Compound III), cyanide (HCN) and acetone (Compound IV) (Westby 2002). 
processes such as grating roots or pounding leaves (Latif and Müller 2015), allowing the substrate (cyanogens) to be catalyzed. Thus the initial grating step is important to help detoxify, that is, to reduce cyanogens. In addition, heating can help cyanide (gas form) to be liberated from the product matrix. By reducing the amount of residual cyanide, heating and physical cell disruption are important to make cassava products safer.

\section{Case study: biofortified cassava roots made into gari and fufu in Nigeria}

\subsection{Project outline}

Vitamin A deficiency is a major public health issue in developing countries and especially in sub-Saharan Africa. In Nigeria, it is estimated that $20 \%$ of pregnant women and about $30 \%$ of children under five are vitamin A deficient (Mainasara 2011). HarvestPlus is currently developing and promoting biofortified cassava (yellow cassava) (Fig. 7) that contains

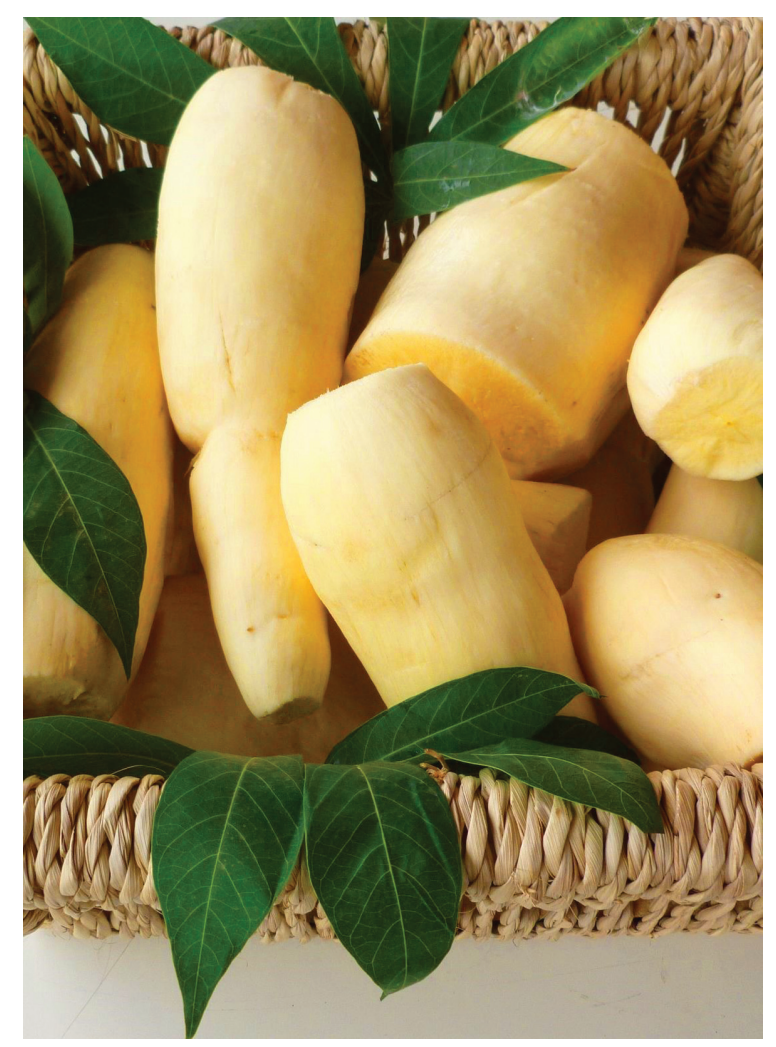

Figure 7 Peeled roots of yellow biofortified cassava and leaves. Source: Bechoff, A., 2013, Nigeria. 
provitamin A carotenoids that could contribute to reducing vitamin A deficiency. Varieties of yellow cassava contain between 5 ppm and 25 ppm (Ceballos et al., 2013) of total carotenoids, whilst non-biofortified (white) varieties have only $0.05-0.35$ ppm (Table 1).

The HarvestPlus-funded project described here (2012-14), led by the NRI, UK investigated the retention of carotenoids and consumer acceptability of yellow varieties of cassava in Nigeria. These yellow varieties were processed into gari and fufu using the traditional methods applied to the local (white) varieties. (Fig. 8 and 9)

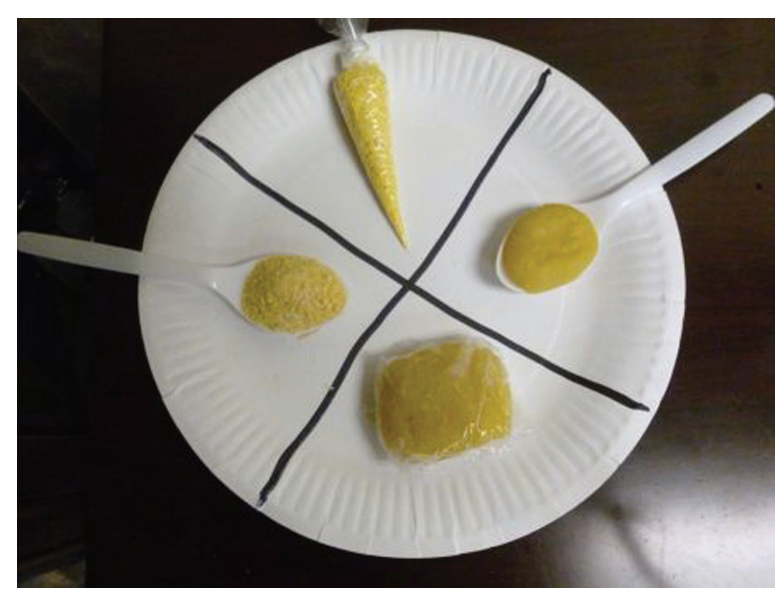

Figure 8 Cassava fufu made from a yellow biofortified variety. Source: Bechoff, A., 2013, Nigeria.

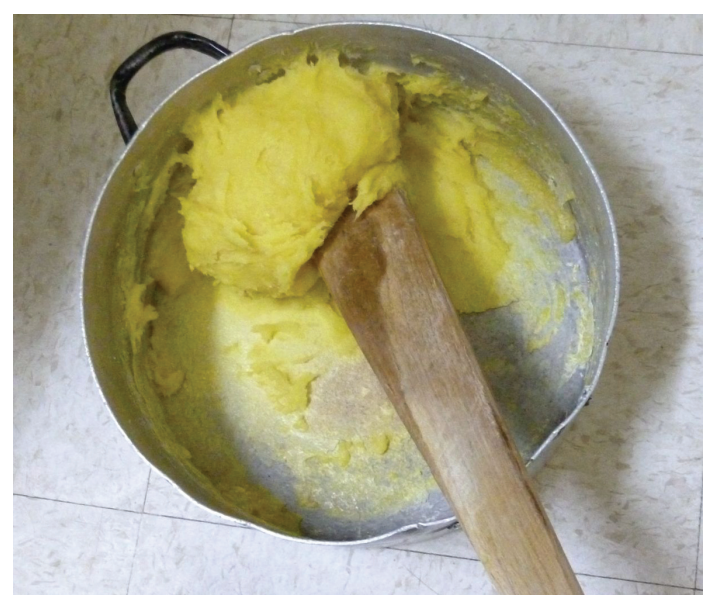

Figure 9 Gari and eba from yellow biofortified cassava. Source: Bechoff, A., 2013, Nigeria. 


\subsection{Project outcomes}

In its raw state, yellow-fleshed cassava mainly contains provitamin A carotenoids. These have been reported to be trans- $\beta$-carotene, 13-cis and 9-cis- $\beta$-carotene (Fig. 10) (Rodriguez-Amaya and Kimura 2004; Chavez et al., 2007; Thakkar et al., 2009).

Provitamin A carotenoids are chemically unstable molecules that are affected by external factors such as temperature, light and oxygen. (Rodriguez-Amaya and Kimura 2004). Hence provitamin A levels in yellow-fleshed cassava can be affected by processes such as gari and fufu production. Therefore, measuring the retention of provitamin A during/ after processing (i.e. gari and fufu) is important to ensure that the biofortified food retains provitamin A levels that could contribute to a significant part of the vitamin A intake of the people who consume it.

Bechoff et al. (2015) demonstrated that carotenoids in gari degraded quickly during storage at ambient temperature: carotenoid content, and hence vitamin $A$ activity of the gari products, decreased markedly with storage time and temperature (Table 2).

This work advises a limited storage period of gari products from yellow cassava at ambient temperature ( 25 days maximum). Gari, eba and fufu made from yellow cassava were well accepted by the local population, but the main issue was the limited shelf life of gari from biofortified cassava. The research overall showed that yellow cassava products have a significant carotenoid content, were well accepted by the local population and could therefore contribute to tackling vitamin A deficiency. These project results have implications for the promotion of yellow biofortified cassava to farmers, processors and different stakeholders in developing countries.

\section{COMMON GEOMETRIC ISOMERS OF $\beta$-CAROTENE}<smiles>CC1=C(/C=C/C(C)=C/C=C/C(C)=C/C=C/C=C(C)/C=C/C=C(C)/C=C/C2=C(C)CCCC2(C)C)C(C)(C)CCC1</smiles>

All-trans- $\beta$-carotene

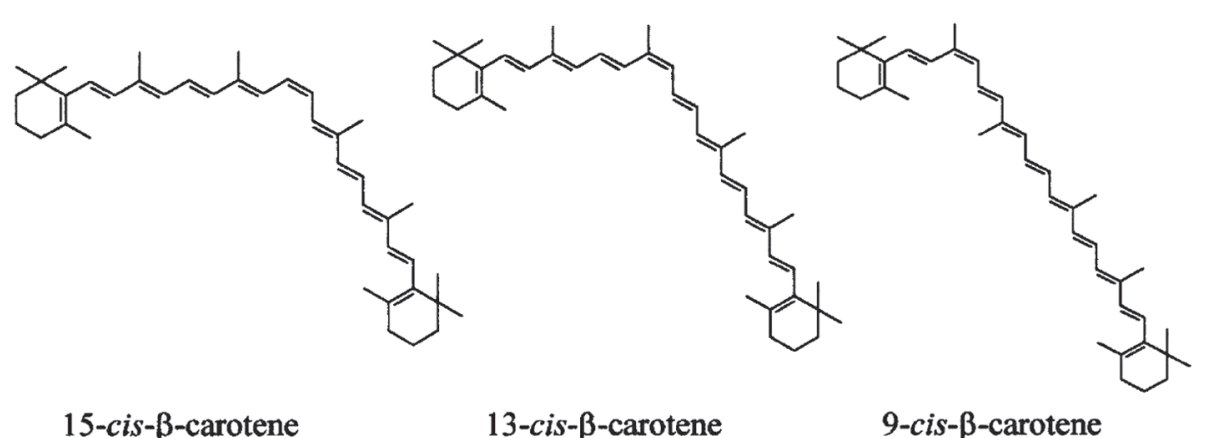

Figure 10 Isomers of $\beta$-carotene. Source: Rodriguez Amaya and Kimura (2004). 
Table 2 Estimation of vitamin A activity ( $\mu$ g retinol equivalent) for a $100 \mathrm{~g}$ portion of gari made from yellow biofortified cassava (BG) and from white cassava with palm oil (RPG) ( $\mu \mathrm{g}$ $\left.R A E^{a}\right)$ during storage and maintained at constant humidity $\left(a_{w}=0.5\right.$ for $\left.\mathrm{NaBr}\right)$

\begin{tabular}{|c|c|c|c|c|c|}
\hline \multicolumn{2}{|c|}{ RAE ${ }^{a}$ estimate } & \multicolumn{2}{|l|}{$5: 1^{b}$} & \multicolumn{2}{|l|}{$12: 1^{b}$} \\
\hline $\mathrm{T}\left({ }^{\circ} \mathrm{C}\right)$ & Storage days & $B G$ & RPG & BG & RPG \\
\hline & Initial & $301 \pm 7$ & $203 \pm 6$ & $126 \pm 3$ & $85 \pm 2$ \\
\hline \multirow[t]{4}{*}{19} & 24 & $256 \pm 11$ & $209 \pm 11$ & $107 \pm 5$ & $87 \pm 4$ \\
\hline & 49 & $205 \pm 5$ & $161 \pm 24$ & $85 \pm 2$ & $67 \pm 10$ \\
\hline & 60 & $200 \pm 7$ & $175 \pm 13$ & $83 \pm 3$ & $73 \pm 5$ \\
\hline & 80 & $156 \pm 9$ & $140 \pm 18$ & $65 \pm 4$ & $58 \pm 8$ \\
\hline \multirow[t]{5}{*}{26} & 18 & $245 \pm 23$ & $181 \pm 8$ & $102 \pm 10$ & $75 \pm 3$ \\
\hline & 24 & $250 \pm 26$ & $190 \pm 11$ & $104 \pm 11$ & $79 \pm 4$ \\
\hline & 49 & $150 \pm 29$ & $135 \pm 7$ & $63 \pm 12$ & $56 \pm 3$ \\
\hline & 60 & $130 \pm 20$ & $154 \pm 9$ & $54 \pm 8$ & $64 \pm 4$ \\
\hline & 80 & $99 \pm 15$ & $130 \pm 12$ & $41 \pm 6$ & $54 \pm 5$ \\
\hline \multirow[t]{6}{*}{33} & 10 & $201 \pm 14$ & $148 \pm 16$ & $84 \pm 6$ & $61 \pm 6$ \\
\hline & 18 & $204 \pm 12$ & $200 \pm 6$ & $85 \pm 5$ & $83 \pm 2$ \\
\hline & 24 & $172 \pm 15$ & $189 \pm 8$ & $72 \pm 6$ & $79 \pm 3$ \\
\hline & 49 & $87 \pm 7$ & $137 \pm 10$ & $36 \pm 3$ & $57 \pm 4$ \\
\hline & 60 & $58 \pm 2$ & $123 \pm 6$ & $24 \pm 1$ & $51 \pm 2$ \\
\hline & 80 & $41 \pm 3$ & $93 \pm 4$ & $17 \pm 1$ & $39 \pm 2$ \\
\hline \multirow[t]{7}{*}{40} & 10 & $148 \pm 26$ & $164 \pm 5$ & $62 \pm 11$ & $68 \pm 2$ \\
\hline & 18 & $140 \pm 7$ & $183 \pm 5$ & $58 \pm 3$ & $76 \pm 2$ \\
\hline & 24 & $99 \pm 3$ & $157 \pm 9$ & $41 \pm 1$ & $65 \pm 4$ \\
\hline & 31 & $68 \pm 2$ & $144 \pm 7$ & $28 \pm 1$ & $60 \pm 3$ \\
\hline & 49 & $29 \pm 2$ & $99 \pm 3$ & $12 \pm 1$ & $41 \pm 1$ \\
\hline & 60 & $21 \pm 1$ & $80 \pm 7$ & $9 \pm 0.4$ & $33 \pm 3$ \\
\hline & 80 & $12 \pm 0.2$ & $42 \pm 1$ & $5 \pm 0.1$ & $18 \pm 0.3$ \\
\hline
\end{tabular}

Mean of triplicate determinations \pm standard deviation. ${ }^{a}$ Retinol Activity Equivalent. ${ }^{\mathrm{b}} \mathrm{RAE}$ was calculated for a bioconversion factor of 5:1 (La Frano et al., 2013) estimate $=\{$ All-trans- $\beta$-carotene content $/ 5+$ minor $\beta$-carotene content/10 $\times$ unit $(\mathrm{g})$ or for a bioconversion factor of 12:1 (National Academy of Sciences/ Institute of Medicine 2001). Classical estimate $=\{$ All-trans- $\beta$-carotene content $/ 12+$ minor $\beta$-carotene content/24\} $\times$ unit (g). Minor compounds are epoxy and cis $\beta$-carotene that are estimated to possess half of trans $\beta$-carotene activity.

\section{Future trends}

The presence of anti-nutrients, especially cyanogenic compounds, is a major factor for the safe consumption of cassava roots and leaves. Adequate processing is required to detoxify these products to an acceptable and safe level. However, extensive processing 
can also result in loss of nutritional components such as vitamins (i.e. vitamin A, B and C), denaturation of the proteins and loss of the minerals due to leaching. Retention studies are needed to better understand effects of specific processes and storage conditions. On the one hand, research should look at the preservation of nutritive value in cassava roots and leaves; on the other hand, it should consider reaching a safe level for detoxification of cyanogenic compounds.

Cassava roots are poor in micronutrients such as vitamin A, zinc and iron and also in protein. Breeders have been working on improving the nutritional value of cassava roots using mainly conventional breeding, but also genetic engineering. Thanks to breeding efforts, carotenoid content in the cassava roots have reached a level that was beyond initial expectations (up to $25 \mathrm{ppm}$ ). There is still considerable debate among nutritionists and breeders with regard to best approaches to improve mineral and protein nutrition in deficit populations - whether to focus on diet diversity or biofortification through breeding. Both approaches have merit and challenges, and some combination seems prudent.

Cassava leaves are more nutritious but their use is still unexploited in places where cassava is mostly grown for its roots. Leaves may be underutilized because of their high level of toxicity compared to roots, but there might also be a lack of awareness in local populations who consume roots about the nutritional content and palatability of leaves. There is potential to promote cassava leaves; however, research on the types of dishes suiting the local population, consumer acceptance of cassava leaves and modifying food habits is required. Education on the uses of cassava leaves (including farming management of the leaf harvest to optimize and balance income and nutrition through combined leaf and root yields) should be undertaken as part of the promotion of cassava leaves.

\section{Conclusion}

Cassava is an important staple crop in developing countries, and contributes to food security of millions of people, especially poor smallholder farmers in sub-Saharan Africa. Products from cassava roots are incredibly diverse and vary from country to country, and among ethnic groups. The types of products are linked to tradition, convenience, access to processing resources and, very importantly, the need for detoxification of cassava roots and leaves that contain cyanogenic glucosides. Roots of sweet varieties (low cyanogen content) require little processing; a single step such as boiling or frying is sufficient to bring the level under the safe level of 10 ppm recommended by the Food Agriculture Organization. On the other hand, bitter varieties (average to high cyanogen content) of roots require more extensive processing. Grinding, pounding and heating are among the steps that help detoxify the cassava by enzymatic catalysis of cyanogens (releasing naturally present enzymes in the cassava) and liberation of cyanide. Products can be fermented by submersion in water or as a mash (solid-state fermentation). Some products are dried (i.e. gari, attieke and flour) and others are processed as 'wet' (fufu, agbelima, chikwangue etc.). Processes for cassava leaves are not as varied as for roots; the general steps are grinding or pounding, followed by cooking. The variants in leaf processing are mostly from the different ingredients added to the leaves and the duration of cooking. Roots and leaves are good sources of potassium, magnesium, and vitamins B and $C$. Whilst roots mainly consist of carbohydrate (starch), leaves have considerably more protein (i.e. especially high lysine content), and also carotenoids that could be complementary from a nutritional 
point of view. Both roots and leaves however are deficient in methionine, an important amino acid for the diet. In addition, levels of zinc and iron are not high enough for roots and leaves to be a substantial source of these essential minerals. Efforts have been made to develop and promote biofortified varieties that contain higher carotenoid contents in the roots (giving them a yellow colour), and there are hopes that these varieties could help tackle vitamin A deficiency.

Nutritional content of cassava varieties can be improved over current levels by 'breeding'. Researchers also need to look at selection in relation to the consumer taste and acceptance in order to promote more nutritional varieties (e.g. biofortified cassava containing carotenoids). Cassava's nutritional drawbacks have led national and international research institutes such as CGIAR, NGOs and the private sector to look for appropriate strategies to solve these challenges using different approaches. Examples are the BioCassavaPlus Programme that is looking at improving the poor nutritional content by developing nutritionally improved varieties using transgenic strategies. Targets for improvement are low cyanogenic potential, pest and disease resistance. PPD resistance, higher and better protein content, and enhanced micronutrient content (i.e. iron, zinc and carotenoids) (Sayre et al., 2011). Other approaches use conventional breeding techniques to improve micronutrients of interest in the cassava roots (i.e. HarvestPlus) (Bouis and Welch 2013). Breeding for nutrition should focus on the people who are food insecure, and on the specific nutrients for which they have the most critical deficits. Education, promotion and effective scaling out of appropriate technologies need to be combined and optimized in order to increase adoption of these varieties by nutritionally vulnerable people.

Understanding potential market demand is paramount. For instance, are there new or improved forms of products from cassava roots and leaves that would be suitable in particular for the growing urban populations in sub-Saharan Africa? This might include dried forms of some of the wet products that could be prepared more quickly than the traditional products (e.g. fufu). The demand for competing products to cassava for starch, such potato, sweet potato, maize and rice should also be considered. In addition, exported cassava of better quality could compete with locally grown cassava, and provide income for diversified diets as compared to direct consumption and high dependence on cassava. These points should be taken into account for the development of cassava products. Cassava leaves also have potential to be used to increase protein and vitamin intake but are still very much underexploited. For instance, the development of cassava leaf protein concentrate could be explored (Latif and Müller 2015). This could help tackle protein and vitamin A malnutrition in some areas where currently only the roots are used for food. Cassava has the potential for impact on nutrition and health through diverse and nutritionally improved products from roots and leaves, and through generation of income from the sales of cassava that can be used indirectly to improve nutrition and health. In order to achieve this, consumers' tastes, nutritional requirements and market demand, all need to be met.

\section{Where to look for further information}

Research Programme on Roots, Tubers and Bananas. Consultative Group for International Agricultural Research (CGIAR) http://www.rtb.cgiar.org 
Natural Resources Institute website and newsletter http://www.nri.org [NRI awarded Queen's Anniversary Prize for ground-breaking work on cassava in 2015] International Society for Tuber and Roots Crops http://www.istrc.org/

\section{References}

Achinewhu, S. C., Barber, L. I. and ljeoma, I. O. (1998). Physicochemical properties and garification (gari yield) of selected cassava cultivars in Rivers State, Nigeria. Plant Foods Hum. Nutr., 52, 133-40.

Agbor-Egbe, T. and Mbome, I. L. (2006). The effects of processing techniques in reducing cyanogen levels during the production of some Cameroonian cassava foods. J. Food Compos. Anal., 19, 354-63.

ARS:846 (2012). Food grade cassava starch specifications CD-ARS 846. First edition 2012. ARSO-201. African Organization for Standardization. https://law.resource.org/pub/ars/ibr/ars.846.2012. pdf.

Bechoff, A., Chijioke, U., Tomlins, K. I., Govinden, P., Ilona, P., Westby, A., and Boy, E. (2015). Carotenoid stability during storage of yellow gari made from biofortified cassava or with palm oil. J. Food Comp. Ana., 44, 36-44.

Blagbrough, I. S., Bayoumi, S. A., Rowan, M. G. and Beeching, J. R. (2010). Cassava: an appraisal of its phytochemistry and its biotechnological prospects. Phytochemistry, 71(17), 1940-51.

Blanshard, A. F., Dahniya, M. T., Poulter, N. H. and Taylor, A. J. (1993). Quality of cassava foods in Sierra Leone. J. Sci. Food Agric., 64(4), 425-32.

Bokanga, M. (1994). Processing of Cassava Leaves for Human Consumption. In International Workshop on Cassava Safety 375, pp. 203-8.

Bouis, H. E. and Welch, R. M. (2013). Biofortification - a sustainable agricultural strategy for reducing micronutrient malnutrition in the global south. Crop Sci., 50, S21-32.

Burns, A. E., Gleadow, R. M., Zacarias, A. M., Cuambe, C. E., Miller, R. E. and Cavagnaro, T. R. (2012). Variations in the chemical composition of cassava (Manihot esculenta Crantz) leaves and roots as affected by genotypic and environmental variation. J. Agric. Food Chem., 60(19), 4946-56.

Cassava Biz (2005). Information service provided by the Integrated Cassava Project (ICP) of the International Institute of Tropical Agriculture (IITA) to encourage, promote and expand agribusiness development in the cassava subsector in Nigeria. http://www.cassavabiz.org/ index.asp.

Ceballos, H., Sánchez, T., Denyer, K., Tofiño, A. P., Rosero, E. A., Dufour, D., Smith, A., Morante, N., Perez, J. C. and Fahy, B. (2007). Induction and identification of a small-granule, high-amylose mutant in cassava (Manihot esculenta Crantz). J. Agric. Food Chem. 56(16), 7215-22.

Ceballos, H., Morante, N., Sánchez, T., Ortiz, D., Aragón, I., Chávez, A. L., Pizarro, M., Calle, F. and Dufour, D. (2013). Rapid cycling recurrent selection for increased carotenoids content in cassava roots. Crop Sci., 53(6), 2342-51.

Charoenkul, N., Uttapap, D., Pathipanawat, W. and Takeda, Y. (2006). Molecular Structure of Starches from Cassava Varieties having Different Cooked Root Textures. Starch, 58(9), 443-52.

Chavez, A. L., Sanchez, T., Ceballos, H., Rodriguez-Amaya, D. B., Nestel, P., Tohme, J. and Ishitani, M. (2007) Retention of carotenoids in cassava roots submitted to different processing methods. J. Sci. Food Agric., 87, 388-93.

Chávez, A. L., Bedoya, J. M., Sánchez, T., Iglesias, C., Ceballos, H. and Roca, W. (2000). Iron, carotene, and ascorbic acid in cassava roots and leaves. Food Nutr. Bull. Suppl., 21(4), 410-3.

Chávez, A. L., Sánchez, T., Jaramillo, G., Bedoya, J., Echeverry, J., Bolanos, E. A., Ceballos, H. and Iglesias, C. A. (2005). Variation of quality traits in cassava roots evaluated in landraces and improved clones. Euphytica, 143(1-2), 125-33. 
Djeni, N. T., N'Guessan, K. F., Toka, D. M., Kouame, K. A. and Dje, K. M. (2011). Quality of attiéké (a fermented cassava product) from the three main processing zones in Côte d'lvoire. Food Res. Int., 44(1), 410-6.

Dziedzoave, N. T. (1996). Quality control studies on agbelima - development of quality specification and evaluation of cassava varieties for processing. MSc thesis submitted to the Department of Biochemistry, University of Science and Technology, Kumasi, Ghana.

Dziedzoave, N. T., Ellis, W. O., Oldham, J. H. and Osei-Yaw, A. (1999). Subjective and objective assessment of agbelima (cassava dough) quality. Food Control, 10(2), 63-7.

Dziedzoave, N. T., Ellis, W. O., Oldham, J. H. and Oduro, I. (2000). Optimizing agbelima production: varietal and fermentation effect on product quality. Food Res. Int., 33(10), 867-73.

Falade, K. O. and Akingbala, J. O. (2010). Utilization of cassava for food. Food Rev. Int., 27(1), 51-83.

FAOSTAT (2013). Statistical Databases. Food and Agriculture Organization of the United Nations. Cassava production and consumption in 2013. http://faostat.fao.org/(accessed on 10th Feb. 2015).

Hongbété, F., Mestres, C., Akissoë, N., Pons, B., Hounhouigan, D. J., Cornet, D. and Mathurin, N. C. (2011). Effects of cultivar and harvesting conditions (age, season) on the texture and taste of boiled cassava roots. Food Chem., 126(1), 127-33.

Irtwange, S. V. and Achimba, O. (2009). Effect of the duration of fermentation on the quality of Gari. Curr. Res. J. Biol. Sci., 1(3), 150-4.

La Frano, M. R., Woodhouse, L. R., Burnett, D. J., Burri, B. J. (2013). Biofortified cassava increases $\beta$-carotene and vitamin A concentrations in the TAG-rich plasma layer of American women. Br. J. Nutr., 110, 310-20

AQ: Please

Latif, S. and Müller, J. (2015). Potential of cassava leaves in human nutrition: A review. Trends in Food Sci. \& Tech., 44(2), 147-58.

Lancaster, P. A., and Brooks, J. E. (1983). Cassava leaves as human food. Economic Botany, 37(3), $331-48$.

Mainasara, A. (2011). Scientists develop Vitamin A cassava in Nigeria, to tackle malnutrition in Africa. Africa Science News. http://www.africasciencenews.org/en/index.php/life-and-style/49food/261-scientists-develop-vitamin-a-cassava-in-nigeria-to-tackle-malnutrition-in-africa-.

Maziya-Dixon, B., Dixon, A. G. O. and Ssemakula, G. (2009). Changes in total carotenoid content at different stages of traditional processing of yellow-fleshed cassava genotypes. Int. J. Food Sci. Tech., 44, 2350-7.

Montagnac, J. A., Davis, C. R. and Tanumihardjo, S. A. (2009). Nutritional value of cassava for use as a staple food and recent advances for improvement. Compr. Rev. Food Sci. Food Saf., 8(3), 181-94.

National Academy of Sciences/Institute of Medicine (2001). Vitamin A. In Dietary Reference Intakes for Vitamin A, Vitamin K, Arsenic, Boron, Chromium, Copper, lodine, Iron, Manganese, Molybdenum, Nickel, Silicon, Vanadium, and Zinc. Washington, DC, USA: National Academy Press.

O'Brien, G. M., Mbome, L., Taylor, A. J. and Poulter, N. H. (1992). Variations in cyanogen content of cassava during village processing in Cameroon. Food Chem., 44(2), 131-6.

Oyewole, O. B. and Odunfa, S. A. (1992). Extracellular enzyme activities during cassava fermentation for 'fufu' production. World J. Microbiol. Biotechnol., 8(1), 71-2.

Owuamanam, C. I., Iwouno, J. O., Ihediohanma, N. C. and Barber, L. I. (2010). Cyanide reduction, functional and sensory quality of gari as affected by $\mathrm{pH}$, temperature and fermentation time. Pak. J. Nutr., 9(10), 980-6.

Oyewole, O. B. and Ogundele, S. L. (2004). Effect of length of fermentation on the functional characteristics of fermented cassava 'fufu'. Journal of Food Technology in Africa, 6(2), 38-40.

Padonou, W., Mestres, C. and Nago, M.C. (2005). The quality of boiled cassava roots: instrumental characterization and relationship with physicochemical properties and sensorial properties. Food Chem., 89(2), 261-70.

Rodriguez Amaya D.B. and Kimura M. (2004). Harvestplus Handbook for Carotenoid Analysis. Copyright HarvestPlus, Washington, DC, 63p. 
Sánchez, T., Salcedo, E., Ceballos, H., Dufour, D., Mafla, G., Morante, N., Calle, F., Pérez, J. C., Debouck, D., Jaramillo, G. and Moreno, I. X. (2009). Screening of starch quality traits in cassava (Manihot esculenta Crantz). Starch, 61(1), 12-19.

Sánchez, T., Dufour, D., Moreno, I. X. and Ceballos, H. (2010). Comparison of pasting and gel stabilities of waxy and normal starches from potato, maize, and rice with those of a novel waxy cassava starch under thermal, chemical, and mechanical stress. J. Agric. Food Chem., 58(8), 5093-9.

Sanni, L., Maziya-Dixon, B., Iwuoha, C., Ilona, P., Akoroda, M., Lemchi, J. and Ogbe, F. (2005). Yield, proximate, and sensory properties of Kpokpogari from 43 Cassava Mosaic Disease varieties. In African Crop Science Conference Proceedings, 7, 597-602.

Sayre, R., Beeching, J. R., Cahoon, E. B., Egesi, C. Fauquet, C., Fellman, J., Fregene, M., Gruissem,W., Mallowa, S. Manary, M., Maziya-Dixon, B., Mbanaso, A., Schachtman, D. P., Siritunga, D., Taylor, N., Vanderschuren, H. and Zhang, P. (2011). The BioCassava Plus Program: biofortification of cassava for sub-Saharan Africa. Annu. Rev. Plant Biol., 62, 251-72.

Thakkar, S. K., Huo, T., Maziya-Dixon, B. and Failla, M. L. (2009). Impact of style of processing on retention and bioaccessibility of -carotene in cassava (Manihot esculanta, Crantz). J. Agric. Food Chem., 57, 1344-8.

Tomlins, K., Sanni, L., Oyewole, O., Dipeolu, A., Ayinde, I., Adebayo, K. and Westby, A. (2007). Consumer acceptability and sensory evaluation of a fermented cassava product (Nigerian fufu). J. Sci. Food Agric., 87(10), 1949-56.

Treche, S., Avoumpo, E. and Adoua-Oyila, G. M. (1995). Notoriété et acceptabilité de la chikwangue Agricongo à Brazzaville, pp. 218-30. Eds., ORSTOM, Montpellier, France.

USDA (2015). National Nutrient Database for Standard Reference http://ndb.nal.usda.gov/ndb/ foods $/ \mathrm{show} / 2943 \mathrm{fg}=$ andman $=$ andlfacet $=$ andcount $=$ andmax $=25$ andsort=andqlookup $=$ cassav aandoffset $=$ andformat $=$ Statsandnew=andmeasureby $=$. Accessed 10 February 2015.

Westby, A. (2002). Cassava utilization, storage and small-scale processing. In R. J. Hillocks, J. M. Thresh and A. C. Bellotti (eds), Cassava Biology, Production and Utilization, pp. 281-300, Oxon, UK: CABI Publishing. 
